\title{
MANAGING NATURAL DISASTERS IN HISTORIC AREAS: A NOVEL HOLISTIC SEISMIC RISK ASSESSMENT METHOD APPLIED TO A RELEVANT CASE STUDY
}

\author{
M. LUCESOLI ${ }^{1}$, G. BERNARDINI ${ }^{1}$ AND E. QUAGLIARINI ${ }^{*}$ \\ ${ }^{1}$ Department of Construction, Civil Engineering and Architecture (DICEA) \\ Università Politecnica delle Marche \\ via di Brecce Bianche 60131 Ancona, Italy \\ e-mail: e.quagliarini@staff.univpm.it (*corresponding author)
}

Keywords: Historic Urban Centre, Urban Paths Network, Seismic Risk Index, Emergency Planning, Risk-Mitigating Solution, Evacuation Strategies

\begin{abstract}
The resilience of historic areas is highly threatened by natural sudden onset events such as earthquakes. Major weak points of an urban environment, widely debated in the past literature, concern mainly masonry buildings. However, also the complex urban paths system could be prone to lose its functionality in the aftermath of a seismic event. Urban paths alterations due to earthquake effects can be attributed to extrinsic (i.e.: ruins formation from buildings) and intrinsic (e.g.: ground instability due to landslide or underground cavities) vulnerability; these factors jointly combined with exposure condition of hosted population in urban areas and with the local seismic hazard represent a possible impediment to evacuation process and at the same time, an obstacle to rescuers' teams occupied in offering a first aid response. Therefore, the work aim is to apply a tool for preliminary evaluation of risk, strictly related to urban paths system considering all abovementioned aspects from a holistic point of view. This goal is achieved by a simplified methodology applicable to a wide-scale on a whole historic centre that takes advantages from a series of easy-to-detect parameters influencing the risk with limited availability of resources. Parameters grouped by topics (i.e.: path use and exposure; geometric features; physicalstructural features; extrinsic vulnerability; seismic hazard) are assigned to scores and weights according to a multi-criteria decision-making process generating a numerical index. A typical Italian urban centre made by historical masonry constructions is assumed as a case study to implement the existing method. The detected risk indexes are then graphically provided through risk maps, a chromatic scale indicates which areas are more prone to possible unavailability of paths rather than others. Evacuation planners and emergency managers could embody this tool in their studies to prevent the high number of losses by guiding evacuees toward assembly points through the risk lower paths and to direct risk-reduction interventions punctually where critical condition emerges with different priority levels. Paths accessibility evaluation through a risk characterization could also result useful as a tool for rescuers' activities optimization and for inhabitant disaster preparedness in terms of being familiar with safest and alternatives paths in emergency conditions.
\end{abstract}




\section{INTRODUCTION}

Historical urban centres in earthquake-prone regions are exposed to severe threats not only referred to the stability of the constructions but principally related to their trapped inhabitants and victims. Preventive measures and actions should be planned to avoid or limit losses especially in these complicated scenarios. Current literature had focused insistently on buildings vulnerability by developed novel interventions techniques or adopting innovative survey tools. The historic built environment cannot be intended as limited to constructions, but it could be a blend of further composing elements [1], two at least: open spaces (e.g.: squares), defined as urban voids where people can gather for everyday life activities in ordinary conditions, but these could become extremely important in an emergency too; moreover, between buildings and open spaces, an interconnection exists embodied by the urban streets defined as an intricate network of paths. The present contribution is mainly centred to the urban paths network without never leave the holistic perspective just introduced above.

Catastrophic effects of an earthquake on populations could be reduced through consciously evacuation procedures that should be preventively planned. Emergency planners necessitate of reliable tools supporting their choices [2], with this aim factors influencing the seismic risk related to the built environment have to be rapidly collected at the wide urban scale to evaluate all the possible scenarios. Focusing on evacuation paths in urban fabrics the risk can be influenced by three main aspects [3]. The first is embodied by the hazard, connected to soil category, morphology and topography, local amplification phenomena [4].

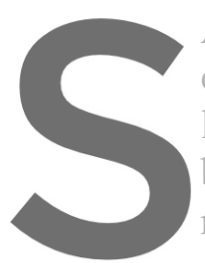
A key role is played by elements composing lifelines) [5] and extri belong to the path itsef narrow streets): Finall constituting the exposur
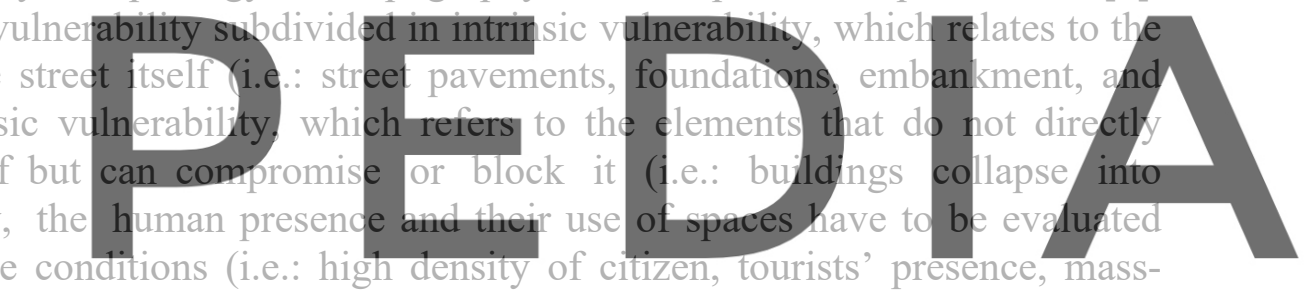
gathering events) [6]

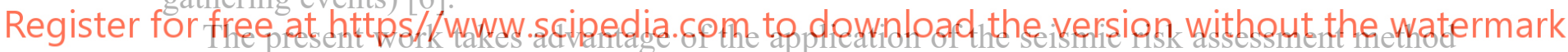
developed by [7] to a significant case study Sulmona (Italy) representative of the central regions of Itaily frequentiy exposed to earthquakes. The work aim is to indicate ad hoc emergency solutions measured on the inquired scenarios for the studied historic centre starting from specific indication provided by the employed method. The multiple capabilities of the method are tested promoting it as a functional supporting tool for emergency management, especially for indicate to rescuers which are the possible higher populated safe areas where to direct their first aid actions and at the same time how they could reach them through the safer and without damages urban paths. This method could be proper to promoting sustainable evacuation strategies or to guide punctual interventions, in case of limited resources, directed to mitigate the seismic risk in historic areas.

\section{MATERIALS AND METHODS}

\subsection{Historic urban area characterization}

Historic parts of urban centres are generally characterized by a complex system made by irregular buildings aggregates that not always follow a specific expansion plan, especially if they are belonging to the mediaeval period (European regions). The most ancient buildings are 
principally made by masonry and they could be affected by serious lacks in their maintenance or could be not well-made, constituting a weak point in case of a seismic event. For these reasons, their vulnerability has to be assessed by taking advantages from the Macroseismic method [8] selected for its rapid application.

Other key components of the historic urban layout are the open spaces that could be privates (e.g.: courtyards, private parking areas, gardens) that are generally fenced and not accessible by pedestrians or public (e.g.: urban squares, widenings street area, parking areas, public parks); these lasts could be assumed as fundamental elements in the emergency planning process. In fact, wide areas dislocated within the built environment must be individuated to host pedestrians during a sudden onset emergency and constitute a safe area where wait for rescuers' arrival and first aids in case of necessity.

Interconnection among buildings stocks and public open spaces are made by streets, in other words, the infrastructure systems play the role of the emergency paths network that should be guaranteed the accessibility to the historic part of the city (to rescuers) and the reachability of safe areas to hosted populations.

The described paths network constituting the urban layout merged among buildings is now categorized in three basic elements: Nodes, Squares, and Links. Nodes are placed at crossroads, at significant plano-alti-metric variation or at the start and endpoint of a specific road structure. Squares are wider nodes that can be considered as assembly points or rescuers' first-aid areas. Finally, a Link is a connection between two consecutive nodes.
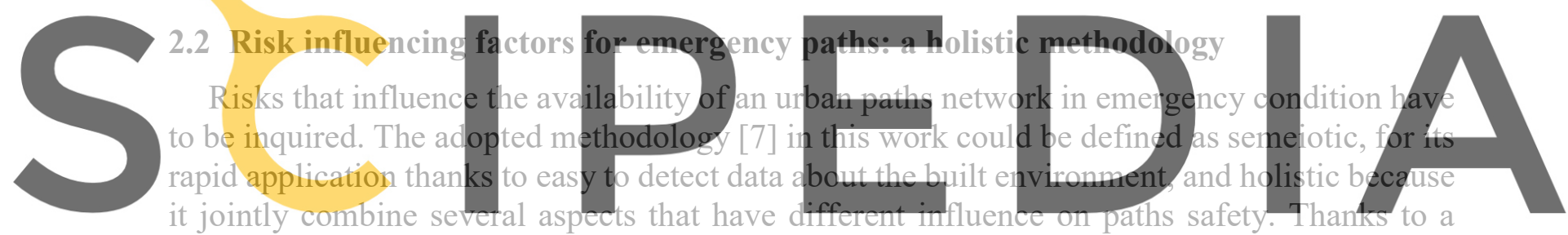

series of alternatives differently weighted related to a list of parameters the method is able to

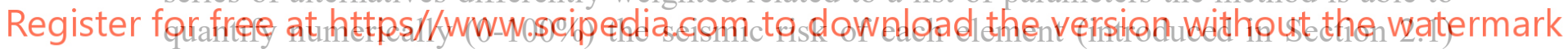
composing the urban layout. For this purpose, a multi-criteria decision-making process is established by grouping parameters in six main topics. The final risk index calculation is achieved by the weighted sum of the Analytical Hierarchy Process [9].

Each risk influencing factors are discussed below following the subdivision in topics:

- The first condition to be established is necessary to guarantee the total accessibility of the link width, however sometimes urban street could be partially obstructed by temporary maintenance interventions on pavements or on facing buildings, in other cases, vehicles access could be impeded by traffic bollards; all these situations that could reduce the ordinary use must be reported;

- Exposure conditions represent a key aspect in emergency conditions to be evaluated under a different point of view. Firstly, in terms of path role and importance that it assumes within the urban fabric during the emergency through a functional analysis. Indeed, certain paths can represent an access route to the urban environment, strategic in emergency phases, or can constitute simply an interconnection among safe areas and strategic buildings defined in the emergency plan. Moreover, links are preferred without barriers, traffic lane dividers or further obstacles that entirely limit the width of lanes. 
A semi-quantitative assessment of the average flow of vehicles and pedestrians highly influence the importance of an urban street, while for squares is involved their intended use (e.g.: wide crossroad characterized by multi-directional movement of both vehicles and pedestrians, pedestrian zone, parking area characterized by possible available areas limitations due to parked vehicles). In addition, other square-specific parameters refer to the presence of architectural elements like street furniture, fences, low walls, trees which could be widespread in the square area and could interfere with pedestrians' motion/rescuers' access or emergency operations;

- Length of the street could affect the travel time required to reach a safe area, while its width can influence the evacuation flows because of interfering obstacles that could also limit the effective width of the path (i.e.: urban furniture; debris presence due to damaged buildings). Longer and narrower paths in the sample are considered more hazardous in respect to the others. For squares, the considered geometrical parameter concerns the area extension;

Street surface conditions (i.e.: asphalted, paved or rough) could influence the streets' accessibility also related to its conservation state causing pedestrians accidents or injuries during the escape. Potential slide down of soil and rocks on both sides of the path and the preventing measures (e.g.: retaining walls) are identified so as to include the linked risks. A specific parameter is also added in this work to include the existence of caves, cisterns and natural or artificial underground structures that are typical of the

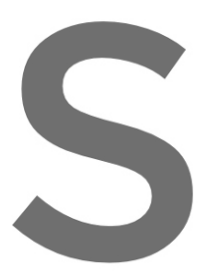
historical urban environment. These subsoil vulnerable elements

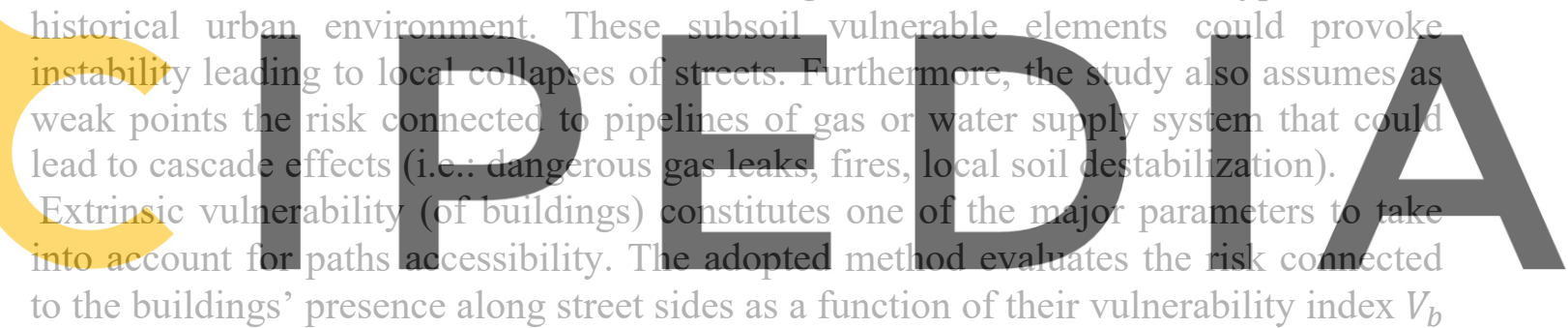

Register for freededthte single building incidence $I_{b}$ on the studied link, defined as the ratio between building $L_{b}$ and link $L$ lengths $\left(I_{b}=L_{b} / L\right)$. For each link $j$ the formulation proposed by [1] permit to quantify this parameter calculating the $V_{\text {link,j }}$ index as shown in Equation (1):

$$
V_{l i n k, j}=\sum_{b \in j} V_{b} * I_{b}
$$

However, in the same scenario, $V_{\text {link, } j}$ values must be normalized by the maximum obtainable and divided into four alternatives according to [10].

- Real cases highlights how both base and local features of soil can be relevant for the paths' damaging, because of cracks or damages occurring on the ground and directly affecting the carriageway state [4]. Proposed methodology, taking advantages from Eurocode 8, evaluates the seismic hazard basing on the design ground acceleration $\left(a_{g}\right)$ [g] related to each seismic zone, to the ground types.

Applying this method, a percentual risk index is associated to each network element (i.e.: nodes, links and squares), for a more comprehensive visualization indexes are graphically returned on risk maps by choosing at least four different colours to diversify values within their variation interval. 


\subsection{Case study individuation: a relevant historic city centre highly prone to earthquakes}

The method is applied to a significant case study from the central region of Italy, the city of Sulmona (AQ) is located in a valley along the Apennine's ridge interested by conspicuous seismic hazard. Within the city centre of about 25.000 inhabitants is possible recognise three main urban areas: the historic centre (of Roman origin) enclosed by two expansion areas one mediaeval and the other erected in the second half of last century. In the 1706 Sulmona know the most violent seismic event (9-10 MCS intensity) that produced over a thousand human life losses and lead to a massive reconstruction of the city. For this reason, the constructive typologies of the historic centre are almost homogeneous, buildings belonging to this area are generally made by massive thickness walls in rough stone punctually improved with regular brick inserts but the masonry quality is very low.

Sulmona is erected in one of the worst zones according to the Italian seismic hazard map [11], its territory is interested by an expected peak ground acceleration (PGA) equal to $0.256 \mathrm{~g}$ and maximum expected magnitude equal to $7.06 \mathrm{Mw}$. The municipal territory extends on seismogenic sources and it is characterized by faults systems in direction NW-SE as it is visible in Errore. L'origine riferimento non è stata trovata. Additionally, the bedrock under the city is located to a depth that varies between 200 and 400 meters left the built areas within the valley exposed to further amplification phenomena due to an alluvial layer of clays. The right side of Errore. L'origine riferimento non è stata trovata. shows a database reporting the main historic seismic events (64 since the IV century) and their intensity during the time.
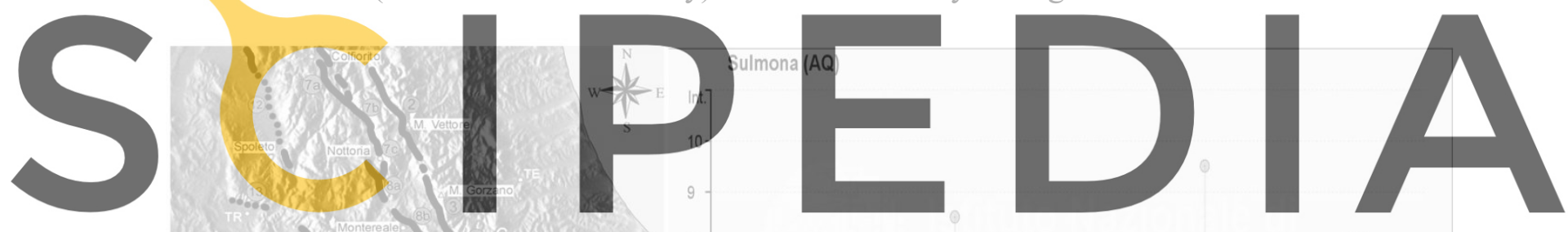

Register for free at https//www.scipedia.єom to download the version without the watermark
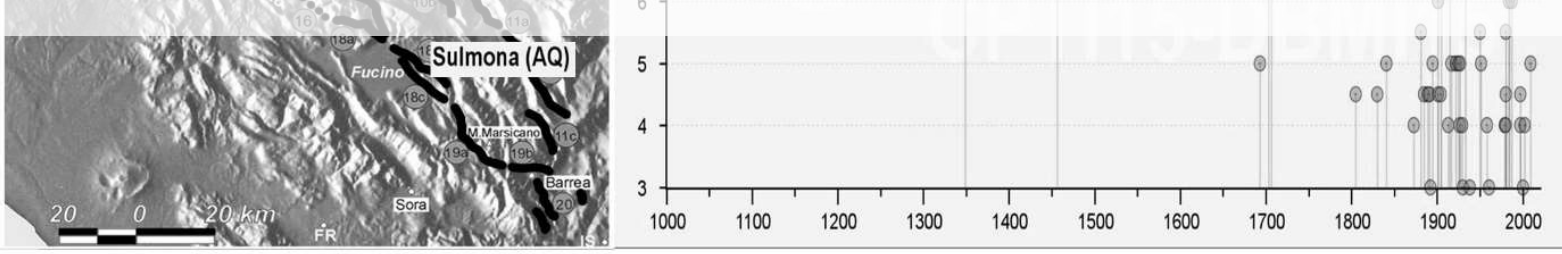

Figure 1: Central Italy faults systems on the left and the seismic history of Sulmona in the right respective sources: https://emidius.mi.ingv.it/GNDT/P512/pictures/lavecchia.jpg and https://emidius.mi.ingv.it/CPTI15DBMI15/query place/(last access: 03/12/19)

The sample choice is relapsed to this urban centre not only because of it has been prone to relevant seismic events but also for the large availability of collected data. In fact, about urban geometry (e.g.: streets width and squares extension) and structural-physical aspects (e.g.: conservation state, streets typologies, morphologic information related to soil, possible landslides) data are obtained through remote data collection technologies (e.g. desktop web mapping services, photographs, aerial maps); more detailed data for instance related to the 
seismic hazard and soil category have obtained by asking directly municipal offices. A different process is followed for data and information related to features and vulnerability values of buildings, these data are collected from [12] where are obtained through the GNDT methodology, however according to Section 2.2 extrinsic vulnerability have to be inquired by employing vulnerability values of [8]. Hence, the translation from one to the other vulnerability index is achieved by establishing a linear correlation on maximum increasing values of a known sample, a similar process has been already experimented also in [13].

\section{RESULTS}

\subsection{Scenario characterization: urban paths network elements}

Errore. L'origine riferimento non è stata trovata. gives a graphical representation of the elements composing the urban paths network (defined in Section 2.1) individuated for the assumed case study. Particular attention is paid for the main urban streets of Sulmona connecting the principal square "Giuseppe Garibaldi" (letter D in the Errore. L'origine riferimento non è stata trovata.) to widening areas immediately out of the historic perimeter of the urban centre that can be considered as safe places ("Access", green arrows in the Errore. L'origine riferimento non è stata trovata.) where waiting for rescuers' arrival (Evacuation Scenario). At the same time, the central square (D) is also able to host thousands of people considering a density of $2 \mathrm{pp} / \mathrm{m}^{2}$ (according to Italian regulations [14]) thank to its considerable dimension of 13.000

of religious events and and tourist for a capaci inquire the risk of pat case of a seismic emerg squares along main streets could constitute a pos
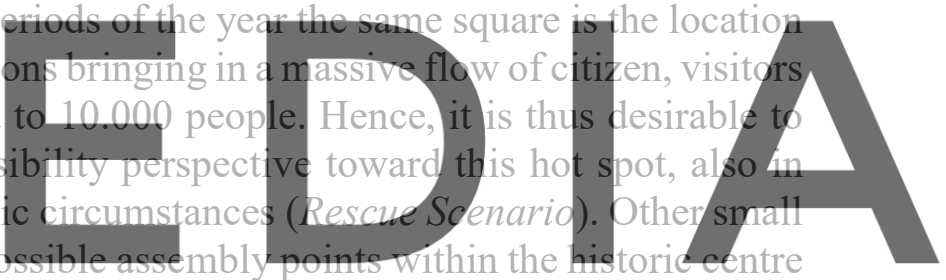

(A, B, C, E, F, and G in Errore. L'origine riferimento non è stata trovata.) where trapped

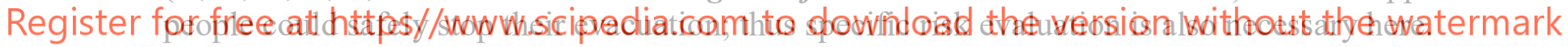

Available data according to Section 2.3 related to the vulnerability of built areas are graphically reported in the Errore. L'origine riferimento non è stata trovata. through the assumption of a chromatic scale, just to give an idea of the location of highly vulnerable masonry structures along urban streets. It is easy to comprehend how the most vulnerable buildings are unfortunately placed on each side of the evacuation paths embodied a serious problem for their availability in the aftermath of a considerable earthquake. These values combined with geometrical features of buildings and street are employed to esteem the extrinsic vulnerability component in the paths risk index assessment methodology (Section 2.2). 


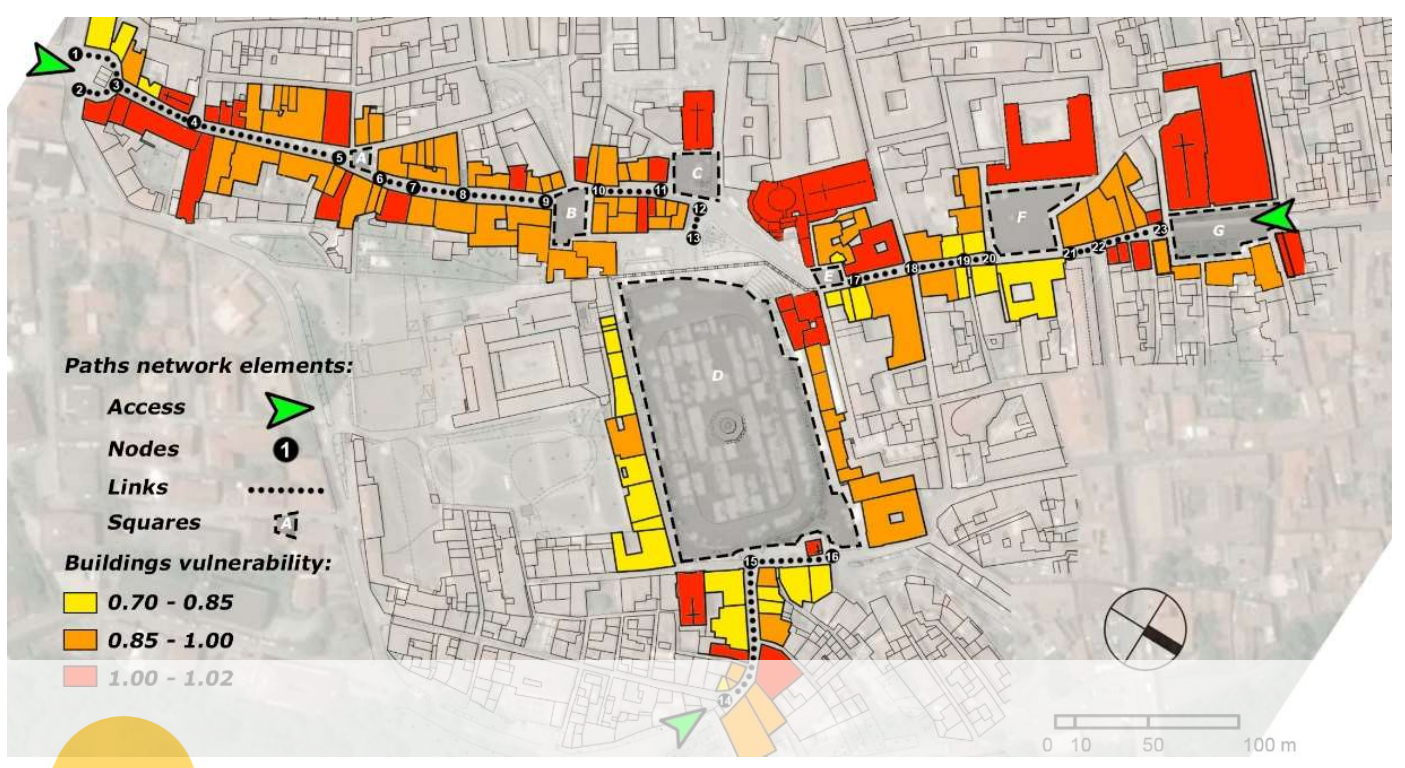

Figure 2: Case study map with the individuation of urban paths network elements and buildings vulnerability.

3.2 Seismic risk entity and mapping, weak points of the emergency paths network

The methodology [7] application highlights from one side, a certain homogeneity in the outcoming risk indexes due to the similar features of inquired links but, from the other side, the

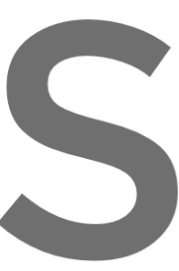

complex situation of the Sulnona's historic dentre especially considered as the main

colours are associated to

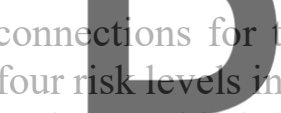

index by dividing into equ

qual parts this interval

Table 1 for each inquired links and squares.

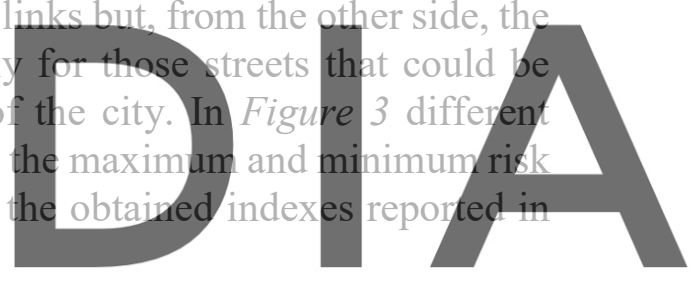

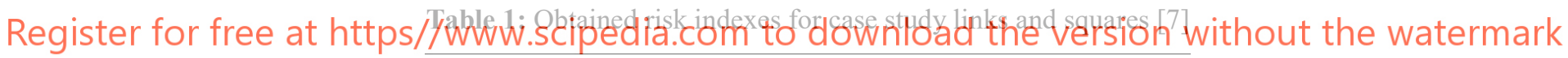

\begin{tabular}{cccc}
\hline Link & Risk index & Square & Risk index \\
\hline $1-3$ & 0.418 & A & 0.489 \\
\hline $2-3$ & 0.402 & B & 0.482 \\
\hline $3-4$ & 0.443 & C & 0.482 \\
\hline $4-5$ & 0.489 & D & 0.470 \\
\hline $6-7$ & 0.459 & E & 0.482 \\
\hline $7-8$ & 0.474 & F & 0.419 \\
\hline $8-9$ & 0.474 & G & 0.482 \\
\hline $11-10$ & 0.482 & & \\
\hline $12-13$ & 0.402 & & \\
\hline $14-15$ & 0.484 & & \\
\hline $15-16$ & 0.419 & & \\
\hline $17-18$ & 0.482 & & \\
\hline $18-19$ & 0.482 & & \\
\hline $19-20$ & 0.435 & & \\
\hline $21-22$ & 0.404 & & \\
\hline $22-23$ & 0.482 & &
\end{tabular}


From the point of view of the Evacuation Scenario, concerning the necessity for pedestrians to leave the historic centre perimeter, from the obtained indexes it emerges that the southern escape route from the "Giuseppe Garibaldi" square is constituted by high-risk links (i.d.:4-5, 6-7, 7-8 and 8-9 in Figure 3); at the same time also the squares displaced along this path are not able to guarantee low levels of risk where evacuees can seek refuge. Additionally, crossing information with the Errore. L'origine riferimento non $\grave{e}$ stata trovata., the same street arch is very long and faced by interminable buildings aggregates with relevant values of vulnerability. Links 17-18 and 18-19 in Figure 3 show a high-risk level but the presence of the $\mathrm{F}$ square reveals the possibility for evacuees to reach it and wait for rescuers' arrival in this safe assembly point, also people coming from the link 22-23 should be conducted to this area instead of the more risky square G. Further consideration could be made by combining also data related to the number of evacuees and the capacity of the single safe areas.

The shortest way to reach a wide and safe area out of the built environment from the "Giuseppe Garibaldi" square could be given by travelling the link 14-15 although it is interested by a high level of risk. The main square D, because of its extension, in case of earthquake occurrence in ordinary conditions (i.e.: without particular events that gather a large mass of people) is able to host a large number of evacuating inhabitants, thus it can be reached by rescuers through the link 14-15 only if no obstruction deriving from the buildings collapse would impede the passage of vehicles (Rescue Scenario).
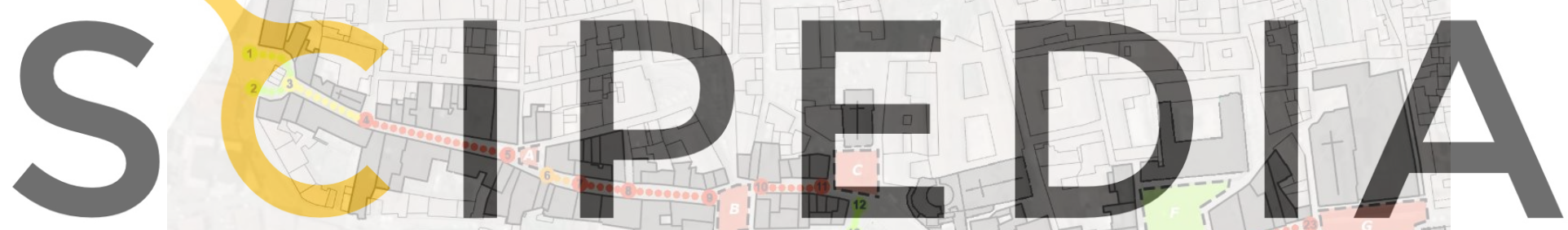

Register for free at https//www.scipedia.com to downioad the version without the watermark

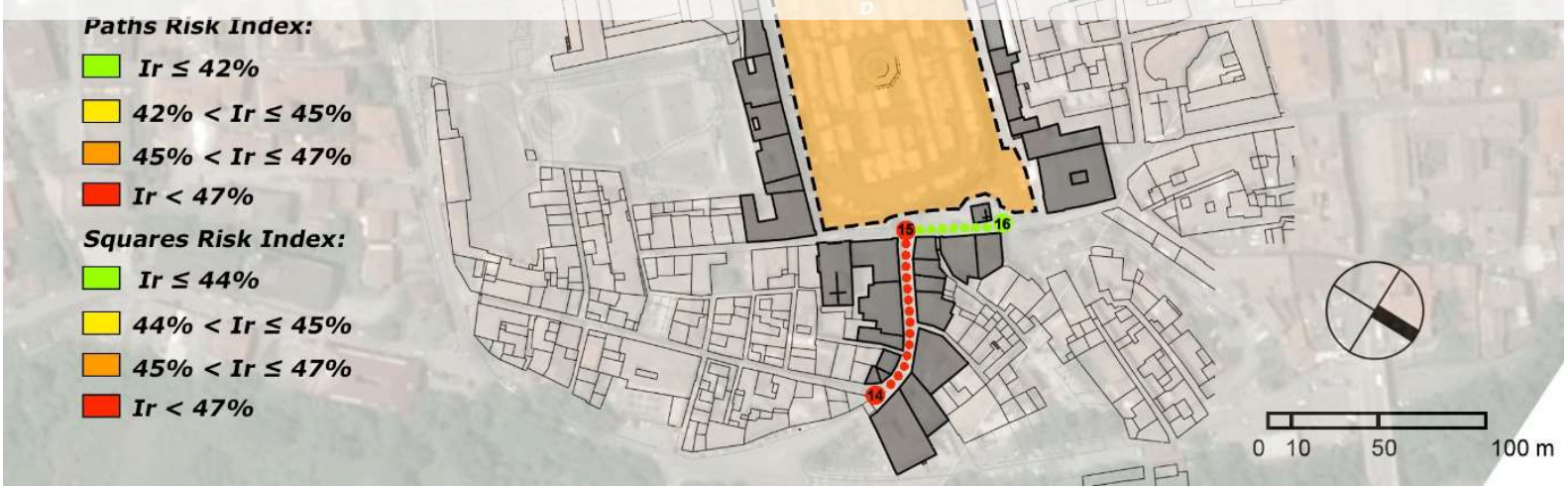

Figure 3: Case study map with the evaluation of the risk indexes for emergency paths and squares along Sulmona's main streets according to the adopted method [7].

\subsection{Proposing risk reduction strategies from risk indexes analysis}

From the results of the previous Section 3.2, three interesting situations emerge and can be 
deeply analysed by proposing evacuation strategies and rescuers' action strictly related to the outcoming data from the applied methodology. Hence, the evaluated risk index for each paths network element is not limited to embody a unique and overall value to quantify the risk but for its structure, it can be decomposed in values referred to each single risk topics (i.e. accessibility, exposure, geometrical features, physical and structural features, extrinsic vulnerability and hazard). Taking advantage of this subdivision the method is capable to justify and determine causes of a high-risk level rather than a low one, in this sense emergency planners can inquire punctually which factor leads to a specific risky situation and they can promote ad hoc interventions.

- The square $\mathrm{F}$ in Figure 4- $A$ shows a low level of risk index in contrast with the other squares along considered paths, from an accurate analysis of single values composing the index it emerges that this urban area is wider than the others (it is detectable making comparisons among geometrical parameters), it is also surrounded by low height building suffered by moderate vulnerability (extrinsic vulnerability parameter) and finally it is can be considered as a pedestrian areas, easily accessible with generally few obstacles and parked vehicles. During a seismic event, trapped people along adjacent riskier links (18-19 and 22-23) have to be guided by placing wayfinding signs (green arrow in Figure 4-A) towards this area, thanks also to the low risk registered for the contiguous links 18-20 and 21-22 (Evacuation Scenario). These last-mentioned links are considered safer than others, in fact, their evaluation reveals a low risk in:
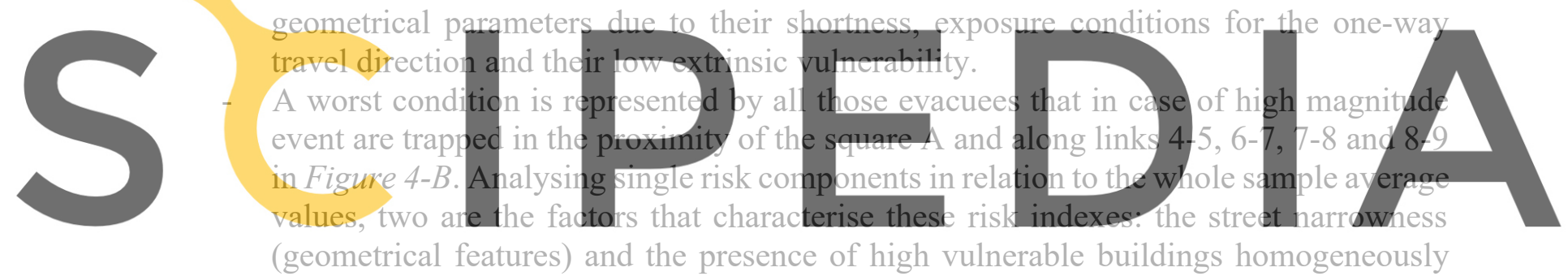

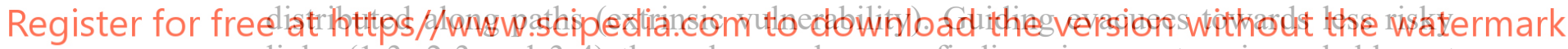
links (1-3, 2-3 and 3-4) through an urban wayfinding signs system is probably not sufficient to guarantee a safe evacuation of this street (Figure 4-B). Further vulnerability analysis should guide planners to indicate precise retrofitting interventions on such buildings to mitigate the risk level (Evacuating Scenario).

- The last issue concerns the Rescue Scenario considering the entrance of rescuers' teams and vehicles within the major square $\mathrm{D}$ capable to gather a large mass crowd of people during an emergency and characterised by a medium risk level. The link 14-15 is the shortest path to reach the gathering area from the road system out of the urban centre (Figure 4-C). For this reason, the exposure parameter is higher rather than other links because it can be considered as a strategic direct access to the historic centre. Extrinsic vulnerability value is high too, but through the investigation on the single buildings vulnerability indexes in Figure 2 is demonstrable how the main problem is represented by the two more vulnerable buildings of the link that are placed on opposite sides in front of each other. In case of a disruptive earthquake, there could be the possibility that buildings collapse could cause an impediment to the vehicles passages due to debris presence. In this case, retrofitting interventions are directed on these single buildings reducing costs related to large scale vulnerability reduction measures, and the final aim 
to obtain a safe access path to the main assembly point is pursued.
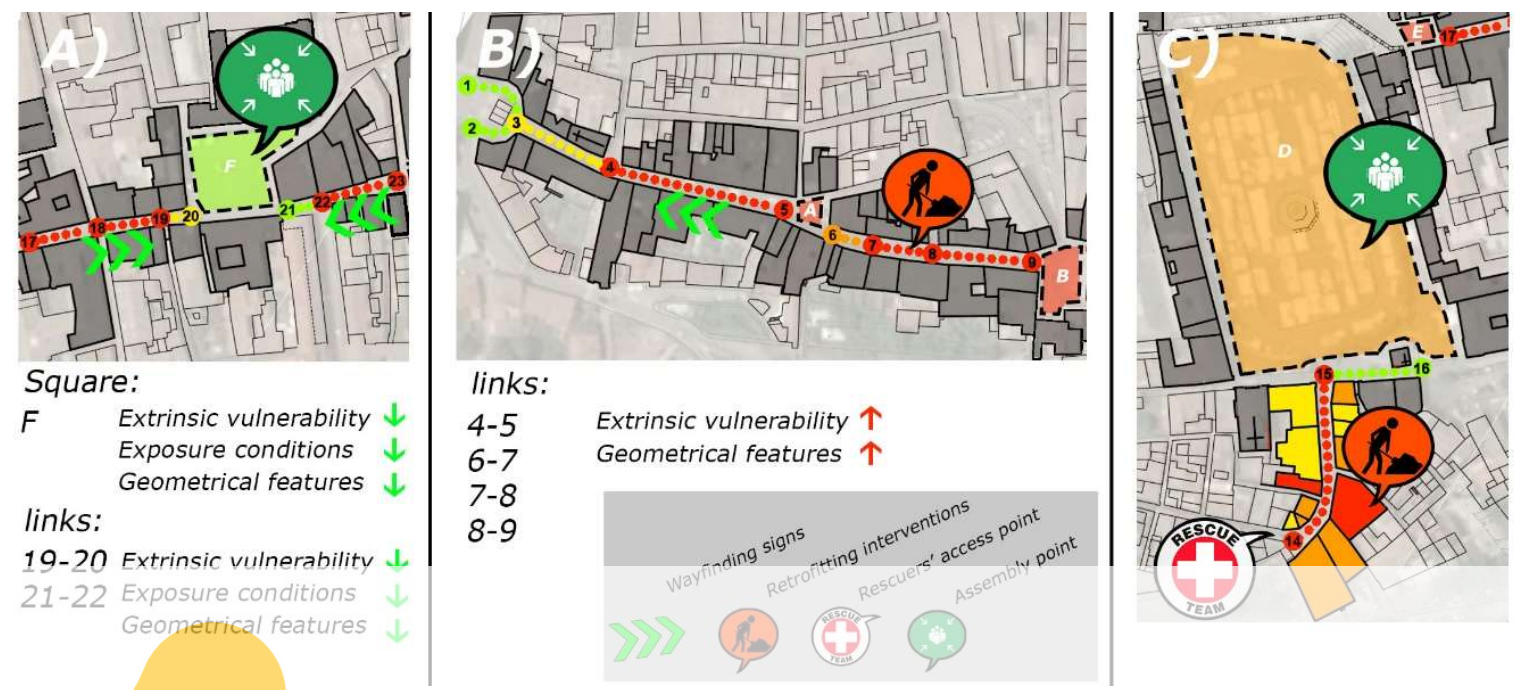

Figure 4: Specific analysis of risk components and mitigating strategies for the three situations (A, B and C).

\section{CONCLUSIONS}

Seismic events could modify the current scenarios in historic urban areas where high density

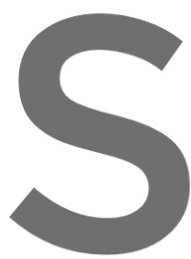

of people and vulnera

usually made by narrow

during their escape or

affecting streets integri

streets, ground failures

emergency phases with adverse effects
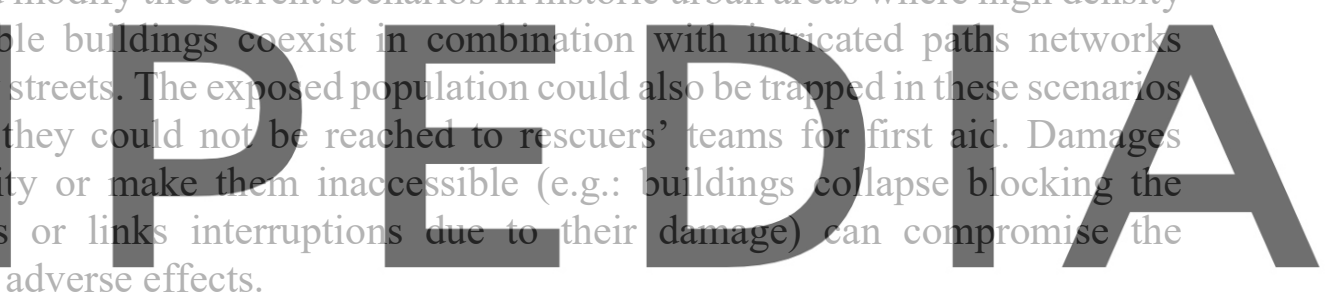

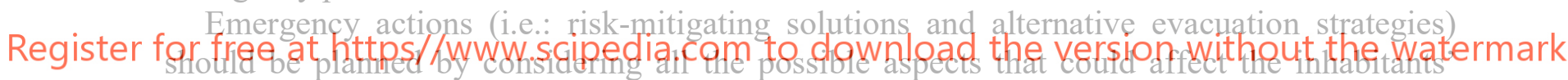

safety. This contribution takes advantage of a holistic methodology able to assess the seismic

risk principaliy of an urban paths network but aiso considering other risk infiuencing factors specifically for the historic urban centre in the post-earthquake scenario (i.e.: vulnerability, hazard, and exposure conditions). Each factor and related parameters are specifically evaluated and assigned to weights and values in order to obtain a numerical risk index. The application of a representative case study in this paper permits to test how it is possible to represent urban fabric criticalities into thematic maps graphically through a discrete risk scale. Moreover, it is possible to realize a deeper analysis of single factors that modify the risk index, promoting specific and punctual intervention with certain priority to allocate the available resources. Making comparison among risk indexes of different strategic paths it is possible to adopt some evacuation strategies rather than the other to better manage the emergency phases. This adopted method ensures the rapidity and easy application that could be preferred instead of models that require onerous and detailed surveys, this advantage can allow to employ it at a wide-scale application that concerns the urban fabric, in the same context, graphical outputs permit to have under control the situation of the overall scenario.

The case study implementation demonstrates the functionality and the reliability of the entire 
process suggesting which links of Sulmona should be excluded from safer paths selection because of their high-risk level, and which could be considered as possible escape routes. As it is demonstrated, results can also be employed to guide rescuers' actions by considering the method as a supporting tool to paths availability assessment and as a standalone procedure to verify or justify adopted approaches within emergency plans.

The work limits are related to the availability of information, especially for data concerning the buildings' vulnerability that are adjusted through a linear regression from other vulnerability indexes based on a limited sample, at the same time these data are not recently updated, the same buildings may have been recently refurbished. In addition, the adopted methodologies to collect the other information (about exposure conditions rather than geometrical features for instance) could be not sufficiently accurate and could be substituted by others more proper.

Future activities may focus on the necessity to esteem (in terms of damages quantity) the built environment alterations related to debris formation and losses of street integrity and availability provoked by earthquakes of different and settable severities. This kind of tool could be combined with the evaluation of criteria related to pedestrians' safer path choice, behavioural aspects and human motion speed which could be integrated into pedestrians' evacuation simulation models.

Acknowledgements. The authors would like to thank Dr. Valeria Neigre for the support in the case study application activities.

\section{REFERENCES}

[1] S. Santarelli, G. Bernardini, E. Quagliarini, M. D’Orazio, New Indices for the Existing City-Centers Streets Network Reliability and Availability Assessment in Earthquake Emergency, Int. J. Archit. Herit. december (2017) 1-16. doi:10.1080/15583058.2017.1328543.

[2] A. Zlateski, M. Lucesoli, G. Bernardini, T.M. Ferreira, Integrating human behaviour and building vulnerability for the assessment and mitigation of seismic risk in historic centres: Proposal of a holistic human-centred simulation-based approach, Int. J. Disaster Risk Reduct. 43 (2019) 101392. doi:10.1016/j.ijdrr.2019.101392.

[3] P. Mouroux, B. Le Brun, Presentation of RISK-UE project, Bull. Earthq. Eng. 4 (2006). doi:10.1007/s10518-006-9020-3.

[4] L. Xinpo, H. Siming, Seismically induced slope instabilities and the corresponding treatments: The case of a road in the Wenchuan earthquake hit region, J. Mt. Sci. 6 (2009) 96-100. doi:10.1007/s11629-009-0197-1.

[5] G. Tesoriere, G. Marinella, M. Russello, Analisi della Vulnerabilità delle Reti Stradali in Aree Soggette a Rischio Sismico, in: XI S.I.I.V, 2001: p. 12.

[6] A. Cherubini, Progetto: SAVE - Strumenti Aggiornati per la Vulnerabilità sismica del patrimonio Edilizio e dei sistemi urbani, TASK 4 - Cap 2. (2003).

[7] E. Quagliarini, G. Bernardini, S. Santarelli, M. Lucesoli, Evacuation paths in historic city centres: A holistic methodology for assessing their seismic risk, Int. J. Disaster Risk Reduct. 31 (2018) 698-710. doi:10.1016/j.ijdrr.2018.07.010.

[8] S. Lagomarsino, S. Giovinazzi, Macroseismic and mechanical models for the vulnerability and damage assessment of current buildings, Bull. Earthq. Eng. 4 (2006) 415-443. doi:10.1007/s10518-006-9024-z. 
[9] T.L. Saaty, The Analytic Hierarchy Process: Planning, Priority Setting, Resource Allocation, McGraw-Hill, 1980. https://books.google.it/books?id=Xxi7AAAAIAAJ.

[10] R. Ferlito, A.G. Pizza, A seismic vulnerability model for urban scenarios. Quick method for evaluation of roads vulnerability in emergency (Modello di vulnerabilità di un centro urbano. Metodologia per la valutazione speditiva della vulnerabilità della viabilità d'emergenza), Ing. Sismica. 4 (2011) 31-43.

[11] Ordinanza Presidente del Consiglio dei Ministri, Opcm 3519 28/04/2006, (2006).

[12] A. Martinelli, L. Corazza, Censimento di vulnerabilita degli edifici pubblici, strategici e speciali nelle regioni Abruzzo, Basilicata, Calabria, Campania, Molise, Puglia e Sicilia: valutazione della vulnerabilità degli edifici pubblici rilevati in 1510 comuni nelle regioni: Abruzz, Dipartimento della protezione civile, 1999.

[13] E. Quagliarini, M. Lucesoli, G. Bernardini, Rapid tools for assessing building heritage's seismic vulnerability: a preliminary reliability analysis, J. Cult. Herit. (2019). doi:10.1016/j.culher.2019.03.008.

[14] Piantedosi Matteo, Circolare del 18 luglio 2018 - N. 11001/1/110/(10) Modelli organizzativi e procedurali per garantire alti livelli di sicurezza in occasione di manifestazioni pubbliche, (2018). 